Supporting Information

\title{
Nanografting of Silanes on Silicon Dioxide with Applications to DNA Localization and Copper Electroless Deposition
}

\author{
Michael V. Lee, Kyle A. Nelson, Laurie Hutchins, Hector A. Becerril, \\ Samuel T. Cosby, Jonathan C. Blood, Dean R. Wheeler, Robert C. Davis, \\ Adam T. Woolley, John N. Harb,* Matthew R. Linford*
}

Department of Chemistry and Biochemistry, Department of Chemical Engineering, and Department of Physics and Astronomy, Brigham Young University, Provo, UT 84602

\section{Experimental}

\section{Neat Silane Monolayer formation}

Silicon wafers bearing native or thermally-grown silicon dioxide were piranha-cleaned (7 parts conc. $\mathrm{H}_{2} \mathrm{SO}_{4}$ to 3 parts $30 \%$ aqueous $\mathrm{H}_{2} \mathrm{O}_{2}$ ) for 10 minutes at $100-130^{\circ} \mathrm{C}$; Caution: piranha solution is extremely dangerous and should be handled with great care) or plasma-cleaned (10-30 seconds on high setting with a PDC-32G instrument from Harrick Plasma, Ithaca, NY) prior to silane application. Wafers were passivated against plating by capping their surface with octyldimethylmonochlorosilane $\left(\mathrm{C}_{8} \mathrm{DMS}\right)$ (Gelest, Morrisville, PA). The passivation step required a wafer to be placed in a clean glass vial and covered with neat $\mathrm{C}_{8} \mathrm{DMS}$. The vial was purged with dry nitrogen, sealed with a septum stopper, and heated to $80^{\circ} \mathrm{C}$ for 20 minutes, which is an adaptation of a literature 
procedure. ${ }^{1}$ Anhydrous methanol was then added and the vial was sonicated. The wafer was removed and rinsed with methanol, and finally placed in a new bath of methanol and sonicated again. The wafer was then rinsed with methanol and dried with a jet of nitrogen.

\section{Nanoshaving and Nanografting}

Silane passivated wafers were patterned with an atomic force microscopy (AFM) tip. Alkylsilane-terminated oxide was nanografted by mechanical removal of the $\mathrm{C}_{8} \mathrm{DMS}$ layer with an AFM tip in the presence of another silane. All AFM patterning and imaging was performed with a Dimension 3100 AFM with a fluid cell (Digital Instruments, Santa Barbara, CA) using high-k $\mathrm{Si}_{3} \mathrm{~N}_{4}$-coated silicon cantilevers (NSC11/Si3N4/AlBS, Mikromasch, Estonia). Forces on the order of $10 \mu \mathrm{N}$ were applied to remove the alkylsilane passivating layers. After nanografting, the samples were removed from the AFM and put in a vial of clean, anhydrous, spectrograde methanol and sonicated for two minutes. The wafer was removed and put in another vial with fresh methanol and sonicated. This was repeated a third time and the sample was blown dry with particle free nitrogen. Following nanografting with APDES and after sonication in methanol the surface in Figure 5 was brushed gently with an aqueous 2 wt. $\%$ soln. of sodium dodecylsulfate; it was then rinsed with Millipore water and blown dry with a gentle flow of nitrogen.

\section{DNA treatment}

The solution of $\lambda$-DNA was $10 \mathrm{ng} / \mu \mathrm{L}$ in TE buffer. The TE buffer was $10 \mathrm{mM}$ Tris and $1 \mathrm{mM}$ EDTA in ultrapure water (Millipore) with $\mathrm{pH}$ adjusted to 7.2 using $\mathrm{NaOH}$. After 
APDES treated wafers were exposed to this solution for $10 \mathrm{~min}$, they were rinsed with ultrapure water and dried.

\section{Plating Chemistry}

A three-step process was followed to provide uniform plating on the amineterminated surfaces. Surfaces were first exposed for 5 minutes to an acidic palladium chloride solution (10 mg $\mathrm{PdCl}_{2}$ in $100 \mathrm{~mL}$ Millipore water plus 10 drops of $37 \% \mathrm{HCl}$ ) diluted 10 times in water. Then they were placed in a solution of $0.15 \mathrm{~g} \mathrm{NaBH}_{4}$ in $25 \mathrm{~mL}$ of Millipore water for 30 seconds to reduce the $\mathrm{Pd}^{2+}$ to $\mathrm{Pd}$. After palladium seeding, the surfaces were immersed in an electroless plating solution $\left(3 \mathrm{~g} \mathrm{CuSO}_{4}, 14 \mathrm{~g}\right.$ potassium sodium tartrate, $4 \mathrm{~g} \mathrm{NaOH}$, and $200 \mathrm{~mL} \mathrm{H}_{2} \mathrm{O}$; combined 80:1 with $37 \%$ formaldehyde in water just prior to plating). ${ }^{2}$

\section{Spectroscopic Ellipsometery}

Ellipsometry measurements were taken with an M-2000D spectroscopic ellipsometer from the J. A. Woollam Company. All measurements were taken at an angle of incidence of $75^{\circ}$ with the full wavelength range (190 to $1000 \mathrm{~nm}$ ). The data were modeled using the optical constants provided with the instrument software for silicon (si_jaw.mat) and silicon dioxide (sio2_jaw.mat). The silicon dioxide model was used to estimate the layer thickness for the silane layers as well as for the silicon dioxide layers. 


\section{Contact Angle Goniometry}

Advancing water contact angles for each surface are reported as the average of measured angles from both sides of a drop on each of 3-4 samples. The angles were measured using a Ramé-Hart model 100-00 goniometer.

\section{X-Ray Photoelectron Spectroscopy (XPS)}

Surfaces were characterized by XPS (ESCA SSX-100, Surface Science) throughout the patterning and plating procedure. Monochromatized Al K $\alpha$ X-rays (1486 $\mathrm{eV}$ ) were used. The instrument employs a hemispherical analyzer with a take-off angle of $52^{\circ}$ from normal. The latest version of the instrument software (ESCA 2005 B v5.01, Service Physics, Bend, OR) was used for data acquisition and analysis.

\section{Process Characterization}

\section{Plating Chemistry}

Because it is possible to more thoroughly characterize planar surfaces than nanoscale features on surfaces, the chemistry reported in the work was validated on planar surfaces before being applied to nanoscale patterns. Accordingly, both $\mathrm{C}_{8} \mathrm{DMS}$-terminated silicon and bare silicon dioxide shards were placed in vials, covered with APDES, purged with dry nitrogen, and sealed with a septum stopper. After an hour of incubation at room temperature, dry methanol was added to the vials by needle through the septum (typically about $4-8 \mathrm{~mL}$ ). Samples were then sonicated inside their vials for 2 minutes. Vials were next opened and wafers were removed and sonicated in clean, dry methanol for 2 
minutes. The wafers were transferred to another vial with new methanol and sonicated a third time for two minutes. Wafers were then dried with nitrogen. Next, these wafers were seeded with $\mathrm{Pd}^{2+}$ and plating was attempted using the same procedure employed in the nanografting experiments. XPS measurements were taken for samples at each step in the process: the initial $\mathrm{C}_{8} \mathrm{DMS}$ or oxide surface (initial), after application of APDES (APDES), and after copper plating $(\mathrm{Cu})$. The resulting XPS ratios to silicon of carbon, nitrogen, palladium, and copper are presented in Supporting Figure 1.

As expected, there is an increase in carbon and nitrogen with the application of APDES to clean oxide samples, but no such increases are observed for the $\mathrm{C}_{8} \mathrm{DMS}$ treated samples. In addition, the only samples that show palladium and copper are the clean oxide samples that have been exposed to APDES and taken through the plating process. The increase in $\mathrm{C} / \mathrm{Si}$ ratio from APDES application to metal plating for the clean oxide samples is likely adventitious carbon depositing on the relatively high free-energy APDES surface; this increase is not observed on the $\mathrm{C}_{8} \mathrm{DMS}$ surfaces where the APDES did not deposit. Palladium and copper were only observed on the oxide samples where the APDES deposited; this leads to the observed attenuation of the N/Si signal after plating on the oxide samples.

The plating solutions were found to change over time. Increased amounts of palladium were found with older solutions, likely due to aggregation of the palladium. The copper electroless solution also degraded over time even without addition of the reducing agent; for optimal results solutions needed to be used within a week of preparation. The large standard deviations for palladium and copper on the plated samples are representative of the variation obtained with different solutions. 
XPS of Octyl and Oxide Surfaces During Patterning
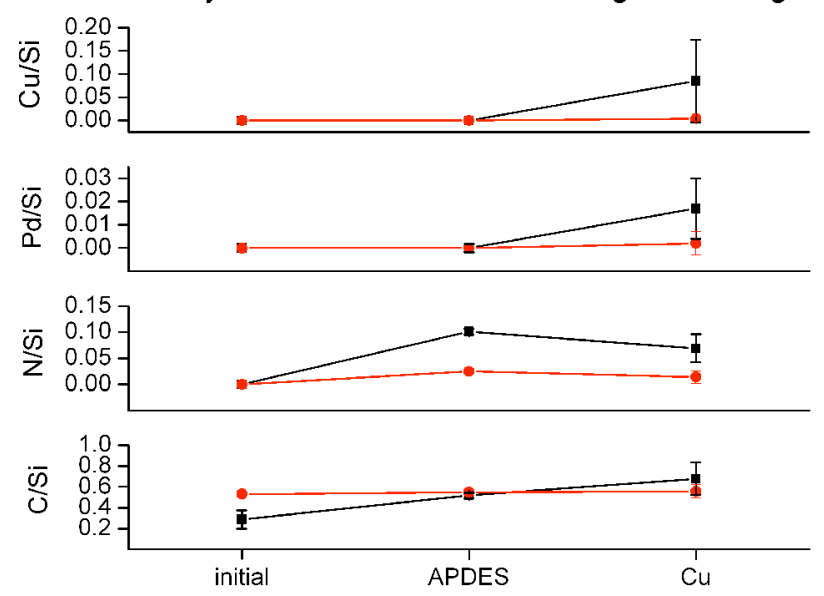

Supporting Figure 1. Ratios to silicon for carbon, nitrogen, palladium, and copper obtained by XPS. Red indicates samples passivated with a layer of $\mathrm{C}_{8} \mathrm{DMS}$, while black indicates oxide samples at each step of the process. Error bars represent the standard deviation for the samples measured.

Table 1 shows the layer thicknesses and advancing water contact angles for each successive surface treatment. The $\mathrm{C}_{8} \mathrm{DMS}$ layer is comparable to the thickness of a layer of an eight carbon, alkene-terminated monochlorosilane that was previously reported. ${ }^{1}$ XPS and the contact angle measurements suggest that there is no significant deposition of APDES on a $\mathrm{C}_{8}$-passivated silicon dioxide surface.

Table 1. Ellipsometric thicknesses and advancing water contact angles with standard deviations for clean silicon dioxide surfaces, silicon dioxide coated with $\mathrm{C}_{8} \mathrm{DMS}$, silicon dioxide coated with APDES, and $\mathrm{C}_{8}$ DMS coated oxide surfaces treated with APDES.

\begin{tabular}{|r|c|c|c|c|}
\hline & \multicolumn{2}{|l|}{ Initial } & \multicolumn{2}{l|}{ APDES treated } \\
\cline { 2 - 5 } & Thickness $(\AA)$ & $\theta_{\text {adv }}$ & Thickness $(\AA)$ & $\theta_{\text {adv }}$ \\
\hline Native $\mathrm{SiO}_{2}$ & $18.1 \pm 3.3$ & completely wet & $7.0 \pm 2.2^{(\mathrm{a})}$ & $61 \pm 3$ \\
\hline${ }^{(\mathrm{a})} \mathrm{C}_{8} \mathrm{DMS}$ & $7.6 \pm 1.2$ & $98 \pm 2$ & $0.0 \pm 1.9^{(\mathrm{b})}$ & $95 \pm 3$ \\
\hline
\end{tabular}

(a) The thickness of the underlying oxide was subtracted from the total measured thickness.

(b) The thickness prior to application of APDES was subtracted from the value measured after application. 


\section{Plating on Nanografted Lines}

Non-specific plating and/or plating outside of the line, which had nucleated at patterned features, was generally observed. Any plating that was observed outside of the lines tended to consist of material that was weakly bound to the substrate and was brushed away by the scanning of the AFM tip in contact mode.

${ }^{1}$ Husseini, G. A.; Peacock, J.; Sathyapalan, A.; Zilch, L. W.; Asplund, M. C.; Sevy, E. T.; Linford, M. R. Langmuir 2003, 19, 5169-5171.

${ }^{2}$ Gutzeit, G.; Saubestre, E. B.; and Turner, D. R. In Electroplating Engineering Handbook Third Edition; Graham, A. K.; Van Nostrand Reinhold Company: New York City, NY, 1971; pp 505. 